\title{
Current status of managing diabetes mellitus in Korea
}

Kyoung Hwa $\mathrm{Ha}^{1,2}$ and Dae Jung Kim ${ }^{1,2}$

${ }^{1}$ Department of Endocrinology and Metabolism and ${ }^{2}$ Cardiovascular and Metabolic Disease Etiology Research Center, Ajou University School of Medicine, Suwon, Korea

\begin{abstract}
Received: August 1, 2016
\end{abstract}
Accepted: August 18, 2016

\section{Correspondence to}

Dae Jung Kim, M.D.

Department of Endocrinology

and Metabolism, Ajou University

School of Medicine, 164 World

cup-ro, Yeongtong-gu, Suwon

16499 , Korea

Tel: $+82-31-219-5128$

Fax: $+82-31-219-4497$

E-mail:djkim@ajou.ac.kr
Diabetes mellitus is an increasing global health problem. Guidelines for diabetic care recommend management of lifestyle and risk factors (glucose, blood pressure, and cholesterol), as well as regular screening for complications associated with treatment of the conditions related to diabetes. The prevalence of diabetes increased from $8.6 \%$ to $11.0 \%$ from 2001 to 2013 . According to the diabetes fact sheet 2015 , the proportion of patients with diabetes treated with antihypertensive medications increased from $56.0 \%$ to $62.5 \%$ from 2006 to 2013 , and $49.5 \%$ of those with diabetes were being treated with lipid-lowering medications in 2013, a 1.8-fold increase since 2006. According to the 2014 Korea National Health and Nutrition Examination Survey data, $45.6 \%$ of patients with diabetes achieved a hemoglobin Arc level of $<7.0 \%, 72.8 \%$ achieved a blood pressure of $<140 / 85 \mathrm{mmHg}$, and $58.0 \%$ achieved a low density lipoprotein cholesterol level of $<100 \mathrm{mg} / \mathrm{dL}$. Only 19.7\% of patients with diabetes had good control of all three of these parameters. Despite improvements in health promotion efforts, the rates of adherence to medication and risk-factor control are low. Therefore, a systematic approach to managing diabetes, including self-management education, is needed to prevent or delay complications. The government needs to establish a long-term policy to address the growing burden of diabetes.

Keywords: Diabetes mellitus; Diabetes management; Korea

\section{INTRODUCTION}

The prevalence of diabetes has increased significantly in recent decades. The International Diabetes Federation stated that 382 million people worldwide suffered from diabetes in 2013, and this number is expected to rise to 592 million by 2035 [1]. Diabetes resulted in 1.3 million mortalities in 2010, which was twice as high as that in 1990 [2]. Furthermore, diabetes-related complications, such as retinopathy, neuropathy, nephropathy, and cardiovascular and cerebrovascular diseases, are increasing the burden on individuals and healthcare systems $[3,4]$. The American Diabetes Association (ADA) and European Association for the Study of Diabetes recommend that the management of patients with type 2 diabetes should include glucose control to achieve a hemoglobin $\mathrm{Arc}(\mathrm{ArC})$ level of $\leq 7 \%$, as well as lifestyle changes, including smoking cessation and control of blood pressure (BP) and lipid levels [5].

\section{PREVALENCE OF DIABETES}

The prevalence of diabetes increased from $8.6 \%$ to $11.0 \%$ from 2001 to 2013 in a nationally representative sample of Koreans aged $\geq 30$ years [6], and the prevalence of diabetes is expected to rise to 5.5 million by 2030 , which is $10.9 \%$ of the adult population aged $\geq 20$ years [7]. Howev- 
er, the number of new patients with diabetes decreased from 2005 to 2009 [8].

The prevalence of diabetes has increased particularly in individuals aged $\geq 70$ years; the rate of diabetes in this age group was $27.6 \%$ in 2013 , which was approximately twice as high as that in 2001 . In addition, the prevalence of diabetes has also increased slightly in younger and middle-aged subjects [6]. The median age of new patients with diabetes decreased by approximately 6 years from 2004 to 2012 [8]. Several studies have shown that the onset of type 2 diabetes at a younger age may lead to poorer glycemic control, greater risk of complications, and higher morality compared with an older age of onset [9-11].

According to the diabetes fact sheet of the Korean Diabetes Association (KDA), the prevalence of prediabetes, defined as a fasting glucose level of 100 to $125 \mathrm{mg} / \mathrm{dL}$, also increased from $21.5 \%$ to $25.0 \%$ from 2006 to 2013 [12]. Annually, $5 \%$ to $10 \%$ of those with prediabetes progress to diabetes, and prediabetes also causes concomitant damage to end organs such as the eyes, kidneys, blood vessels, and the heart $[13,14]$. Considering this situation, effective and diverse strategies to prevent diabetes and prediabetes are needed.

\section{OBESITY AND DIABETES}

Obesity is the most common comorbidity in individuals with type 2 diabetes. In addition, obesity triggers the development of diabetic complications [15]. The ADA recommended obesity control to prevent progression from prediabetes to diabetes and to improve glycemic control in type 2 diabetes [16]. Obesity control also may be necessary for improving high blood pressure and lipid profiles [17].

In Korea, the prevalence of obesity has increased from $29.2 \%$ in 2001 to $31.8 \%$ in 2013 [6]. In particular, the number of obese patients with diabetes has increased. According to a primary care clinic-based survey, $77 \%$ of patients with newly diagnosed diabetes have a body mass index $(\mathrm{BMI})>23.0 \mathrm{~kg} / \mathrm{m}^{2}[18]$. In 2013, the prevalence of obesity/overweight with diabetes was $71.6 \%$ in men and $74.2 \%$ in women [6]. The mean BMI of patients with diabetes increased from 21.9 to $24.8 \mathrm{~kg} / \mathrm{m}^{2}$ over nearly two decades $[19,20]$. Furthermore, an inverse linear relation- ship was detected between BMI and age at diabetes diagnosis among newly diagnosed patients. The mean BMI decreased from $30.4 \mathrm{~kg} / \mathrm{m}^{2}$ in the youngest age group to $24.4 \mathrm{~kg} / \mathrm{m}^{2}$ in the oldest age group $[6,21]$.

\section{MANAGING DIABETES}

The Diabetes Control and Complications Trial (DCCT) and the United Kingdom Prospective Diabetes Study showed that improving glycemic control, lowering BP and lipid levels, and avoiding smoking help reduce microvascular and macrovascular diseases [22-27]. Therefore, guidelines for diabetes care recommend management of lifestyle (diet, weight control, smoking cessation, and physical activity) and risk factors $(\mathrm{A} 1 \mathrm{C}<$ $7.0 \%, \mathrm{BP}<140 / 90 \mathrm{mmHg}$, and low density lipoprotein cholesterol [LDL-C] $<100 \mathrm{mg} / \mathrm{dL}$ ) and regular screening to treat conditions related to diabetes during the early stages [17]. The $2015 \mathrm{KDA}$ 's guideline recommended a $\mathrm{BP}$ target of $<140 / 85 \mathrm{mmHg}$ in patients with diabetes [28].

Because reduced adherence to regimens results in poor health outcomes, comprehensive management of type 2 diabetes should consider adherence to relevant medications [29,30].

According to the $\mathrm{KDA}$, the medication adherence rate, which is estimated using the medication possession ratio, increased from $12.8 \%$ to $44.9 \%$ from 2002 to 2013 [31]. The proportion of patients with diabetes treated with antihypertensive medications increased from $56.0 \%$ to $62.5 \%$ during 2006 to 2013 . Approximately $50 \%$ of patients with diabetes were being treated with lipid-lowering medications in 2013, a 1.8-fold increase since 2006 [12]. According to the 2014 Korea National Health and Nutrition Examination Survey (KNHANES) study, 45.6\% of patients with diabetes achieved $\mathrm{AlC}_{1}<7.0 \%, 72.8 \%$ achieved $\mathrm{BP}<140 / 85 \mathrm{mmHg}$, and $58.0 \%$ achieved LDL-C $<100 \mathrm{mg} / \mathrm{dL}$. Only $19.7 \%$ of patients with diabetes had good control of all three parameters (Fig. 1, unpublished data). Control rates in 2014 improved compared with those from the 2005 health insurance data, in which $40.3 \%$ of patients achieved $\mathrm{AlC}<7.0 \%, 58.6 \%$ achieved $\mathrm{BP}<140 / 90 \mathrm{mmHg}$, and $38.3 \%$ achieved LDL-C $<100$ $\mathrm{mg} / \mathrm{dL}[7,19]$. In particular, the glycemic control rate (defined as $\mathrm{AlC}_{1} \geq 8.0 \%$ ) decreased steadily from $33.6 \%$ in 


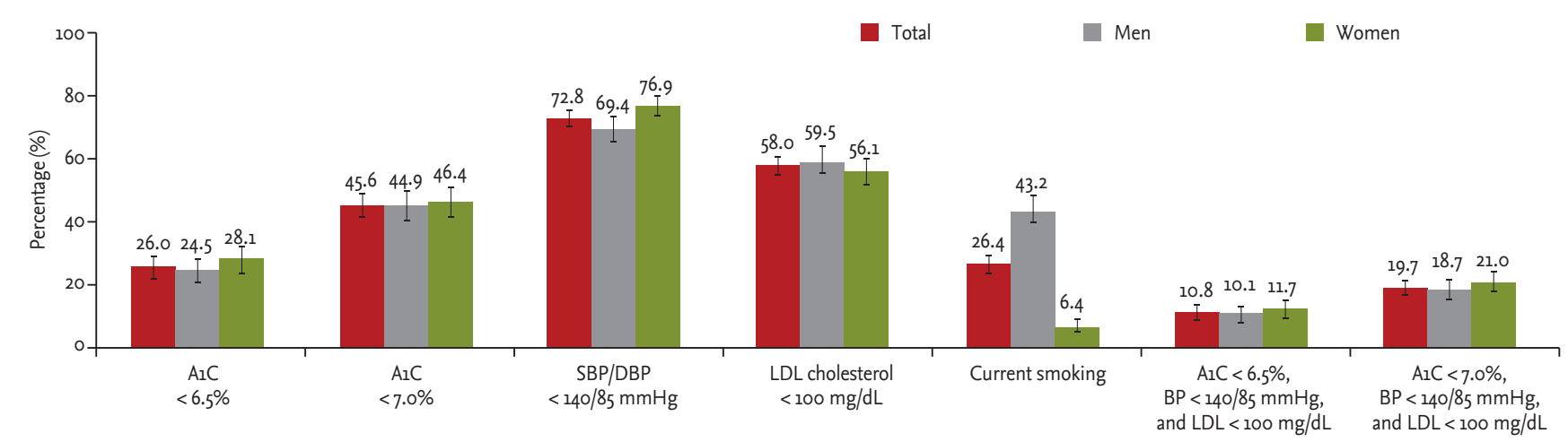

Figure 1. The prevalence of achieving three targets for diabetes management and the smoking status among Korean adults aged $\geq 30$ years diagnosed with diabetes in the 2014 Korea National Health and Nutrition Examination Survey. A1C, hemoglobin A1c; SBP, systolic blood pressure; DBP, diastolic blood pressure; LDL, low density lipoprotein; BP, blood pressure.

2005 to $25.9 \%$ in 2012 to $22.5 \%$ in 2014 (Fig. 2, unpublished data) [19]. Almost half of the male patients with diabetes are still smoking (Fig. 1, unpublished data).

The $\mathrm{ArCl}$ level is considered a clinical marker of diabetes as well as a precise indicator of long-term glycemic control. However, most individuals do not fully comprehend its meaning. Thus, many studies have translated $\mathrm{Al}_{1} \mathrm{C}$ values into blood glucose levels to increase understanding of the clinical implications of $\mathrm{AlC}_{1}$. In Korea, Kim et al. [32] also suggested an association between the mean blood glucose level measured by the oral glucose tolerance test and $\mathrm{A}_{1} \mathrm{C}$, expressed as a linear regression: mean glucose $(\mathrm{mg} / \mathrm{dL})=49.4 \times \mathrm{AlC}(\%)-149.6\left(R^{2}=0.54\right.$, $p<0.001)$. The linear regression equation was fairly dissimilar from that in the $\mathrm{AlC}_{1} \mathrm{C}$ Derived Average Glucose study and DCCT cohort [32].

\section{DIABETES-RELATED COMPLICATIONS}

Diabetes is associated with chronic complications, such as microvascular and macrovascular diseases, and other diseases including dementia and depression [33]. The DCCT/EDIC demonstrated that achieving glycemic control reduces the rate of microvascular complications [34]. Previous studies have shown that the duration of diabetes is associated with an increased risk of micro- and macrovascular complications [35].

The prevalence rates of neuropathy, retinopathy, and nephropathy in Korea are 33.5\%, 20.0\%, and 5.5\%, respectively, in patients with diabetes $[36,37]$. According to the diabetes fact sheet, $1.2 \%$ of patients with type 2 diabetes have end-stage renal disease (ESRD), and 15.9\% have diabetic retinopathy [12]. In particular, the incidence of diabetic nephropathy is increasing rapidly, and it is the most common cause of ESRD [38].

The prevalence rates of cardiovascular, cerebrovascular, and peripheral vascular diseases in patients with type 2 diabetes were $5.5 \%, 5.0 \%$, and 1.1\%, respectively, during 2006 to 2009 according to the Korean National Diabetes Program [39]. The 2009 to 2011 Health Insurance Review and Assessment database indicated that the

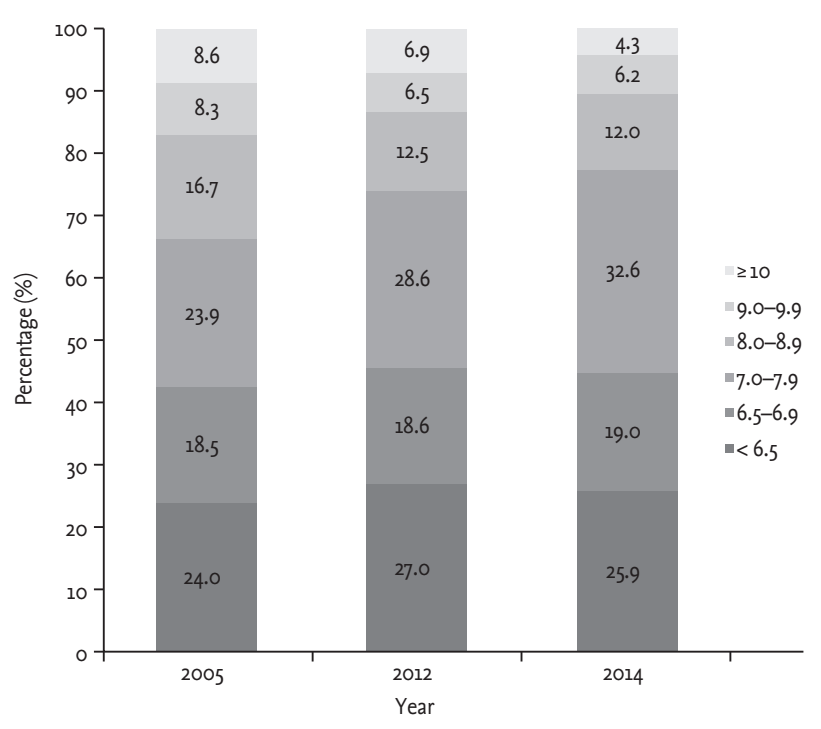

Figure 2. The distribution of patients with diabetes according to hemoglobin Aic levels from the Korea National Health and Nutrition Examination Survey 2005 to 2014. 
prevalence rates of coronary artery, cerebrovascular, and peripheral artery diseases were $14.1 \%, 8.8 \%$, and $0.3 \%$, respectively, in patients newly diagnosed with type 2 diabetes [40]. The presence of macrovascular complications was higher in patients with type 2 diabetes than in those without (295 cases of ischemic stroke, 248 cases of ischemic heart disease, and 41 cases of cerebral hemorrhage/10,000 persons with diabetes; 62 cases of ischemic stroke, 59 cases of ischemic heart disease, and 17 cases of cerebral hemorrhage/10,000 non-diabetic persons) [12].

The prevalence of diabetic complications is expected to increase with the prevalence of diabetes. Regular screening is necessary to prevent complications. However, only $36.3 \%$ and $40.5 \%$ of patients received screening for diabetic retinopathy and nephropathy, respectively, in Korea [41].

Diabetes and cancers are closely linked epidemiologically and biologically. Convincing evidence indicates that diabetes is associated with an increased risk of several types of cancers [42]. The presence of cancer-related hospitalization in Korea was higher in patients with type 2 diabetes than in those without. Specifically, in subjects with type 2 diabetes, the risks of hospitalization events due to stomach, colorectal, liver, pancreatic, and lung cancers were $37.9,43,48,17.6$, and $36 / 10$,000 persons, respectively [12].

Moreover, previous studies reported association between diabetes and risk of psychiatric disorders. The KNHANES reported that diabetes is associated with a marked increase in suicidal ideation and suicide attempts [43,44]. Lee et al. [45] showed that patients with diabetes had a higher risk of mild cognitive impairment that did those without. According to the diabetes fact sheet, the prevalence of dementia in patients with type 2 diabetes increased from $1.2 \%$ to $5.2 \%$ during 2006 to 2013 and was higher than in those without diabetes [12].

\section{CONCLUSIONS}

As the Korean population ages and the prevalence of diabetes increases, it will become increasingly crucial to find ways to overcome associated complications through good diabetes management. Diabetes self-management education is an important element of care for all those with diabetes and those at risk of developing the dis- ease. However, only $39.4 \%$ of patients with diabetes have received comprehensive diabetes self-management education in Korea [7]. Therefore, a systematic approach to manage diabetes, including self-management education, is needed to prevent or delay complications. More concentrated efforts should be focused on early detection and management of diabetic complications and psychiatric disorders. The government needs to establish a long-term policy to address the growing burden posed by diabetes.

\section{Conflict of interest}

No potential conflict of interest relevant to this article was reported.

\section{Acknowledgments}

This research was supported by a grant from the Korea Health Technology R\&D Project through the Korea Health Industry Development Institute, funded by the Ministry of Health and Welfare, Republic of Korea (grant number: $\mathrm{HI}_{13} \mathrm{Co}$ 15).

\section{REFERENCES}

1. Guariguata L, Whiting DR, Hambleton I, Beagley J, Linnenkamp U, Shaw JE. Global estimates of diabetes prevalence for 2013 and projections for 2035. Diabetes Res Clin Pract 2014;103:137-149.

2. Lozano R, Naghavi M, Foreman K, et al. Global and regional mortality from 235 causes of death for 20 age groups in 1990 and 2010: a systematic analysis for the Global Burden of Disease Study 2010. Lancet 2012;380:2095-2128.

3. American Diabetes Association. Economic costs of diabetes in the U.S. in 2012. Diabetes Care 2013;36:1033-1046.

4. Alva ML, Gray A, Mihaylova B, Leal J, Holman RR. The impact of diabetes-related complications on healthcare costs: new results from the UKPDS (UKPDS 84). Diabet Med 2015;32:459-466.

5. Inzucchi SE, Bergenstal RM, Buse JB, et al. Management of hyperglycemia in type 2 diabetes, 2015: a patient-centered approach: update to a position statement of the American Diabetes Association and the European Association for the Study of Diabetes. Diabetes Care 2015;38:140-149.

6. Ha KH, Kim DJ. Trends in the diabetes epidemic in Korea. Endocrinol Metab (Seoul) 2015;30:142-146. 
7. Task Force Team for Basic Statistical Study of Korean Diabetes Mellitus of Korean Diabetes Association, Park Ie B, Kim J, et al. Diabetes epidemics in Korea: reappraise nationwide survey of diabetes "diabetes in Korea 2007". Diabetes Metab J 2013;37:233-239.

8. Song SO, Lee YH, Kim DW, et al. Trends in diabetes incidence in the last decade based on Korean National Health Insurance claims data. Endocrinol Metab (Seoul) 2016;31:292-299.

9. Al-Saeed AH, Constantino MI, Molyneaux L, et al. An inverse relationship between age of type 2 diabetes onset and complication risk and mortality: the impact of youth-onset type 2 diabetes. Diabetes Care 2016;39:823-829.

10. Berkowitz SA, Meigs JB, Wexler DJ. Age at type 2 diabetes onset and glycaemic control: results from the National Health and Nutrition Examination Survey (NHANES) 2005-2010. Diabetologia 2013;56:2593-2600.

11. Wong J, Molyneaux L, Constantino M, Twigg SM, Yue DK. Timing is everything: age of onset influences long-term retinopathy risk in type 2 diabetes, independent of traditional risk factors. Diabetes Care 2008;31:1985-1990.

12. Korean Diabetes Association. Korean diabetes fact sheet 2015 [Internet]. Seoul (KR): Korean Diabetes Association; c2011 [cited 2016 Aug 18]. Available from: http://www.diabetes.or.kr/.

13. Tabak AG, Herder C, Rathmann W, Brunner EJ, Kivimaki M. Prediabetes: a high-risk state for diabetes development. Lancet 2012;379:2279-229o.

14. Nathan DM, Davidson MB, DeFronzo RA, et al. Impaired fasting glucose and impaired glucose tolerance: implications for care. Diabetes Care 2007;30:753-759.

15. Ylitalo KR, Sowers M, Heeringa S. Peripheral vascular disease and peripheral neuropathy in individuals with cardiometabolic clustering and obesity: National Health and Nutrition Examination Survey 2001-2004. Diabetes Care 2011;34:1642-1647.

16. American Diabetes Association. 6. Obesity management for the treatment of type 2 diabetes. Diabetes Care 2016;39 Suppl 1:S47-S51.

17. American Diabetes Association. 8. Cardiovascular disease and risk management. Diabetes Care 2016;39 Suppl 1:S6o-S71.

18. Son JW, Park CY, Kim S, Lee HK, Lee YS; Insulin Resistance as Primary Pathogenesis in Newly Diagnosed, Drug Naïve Type 2 Diabetes Patients in Korea (SURPRISE) Study Group. Changing clinical characteristics according to insulin resistance and insulin secretion in newly diagnosed type 2 diabetic patients in Korea. Diabetes Metab J 2015;39:387-394.

19. Jeon JY, Kim DJ, Ko SH, et al. Current status of glycemic control of patients with diabetes in Korea: the fifth Korea National Health and Nutrition Examination Survey. Diabetes Metab J 2014;38:197-203.

20. Ko KS, Oh TG, Kim CH, et al. A clinical study on the complications of non-insulin-dependent diabetes mellitus in Korea. J Korean Diabetes Assoc 1991;15:257-262.

21. Kim DJ. The epidemiology of diabetes in Korea. Diabetes Metab J 2011;35:303-308.

22. Diabetes Control and Complications Trial Research Group. Effect of intensive diabetes treatment on the development and progression of long-term complications in adolescents with insulin-dependent diabetes mellitus: Diabetes Control and Complications Trial. J Pediatr 1994;125:177-188.

23. The Diabetes Control and Complications Trial (DCCT) Research Group. Effect of intensive diabetes management on macrovascular events and risk factors in the Diabetes Control and Complications Trial. Am J Cardiol 1995;75:894-903.

24. UK Prospective Diabetes Study Group. Tight blood pressure control and risk of macrovascular and microvascular complications in type 2 diabetes: UKPDS 38. BMJ 1998;317:703-713.

25. UK Prospective Diabetes Study (UKPDS) Group. Intensive blood-glucose control with sulphonylureas or insulin compared with conventional treatment and risk of complications in patients with type 2 diabetes (UKPDS 33). Lancet 1998;352:837-853.

26. Gaede P, Vedel P, Larsen N, Jensen GV, Parving HH, Pedersen O. Multifactorial intervention and cardiovascular disease in patients with type 2 diabetes. N Engl J Med 2003;348:383-393.

27. Gregg EW, Li Y, Wang J, et al. Changes in diabetes-related complications in the United States, 1990-2010. N Engl J Med 2014;370:1514-1523.

28. Korean Diabetes Association. Treatment guideline for diabetes 2015 [Internet]. Seoul (KR): Korean Diabetes Association, c2011 [cited 2016 Aug 18]. Available from: http:// www.diabetes.or.kr/.

29. Sabate E. Adherence to long-term therapies: evidence for action [Internet]. Geneva (CH): World Health Organization, c2016 [cited 2016 Aug 18]. Available from: http:// 
www.who.int/chp/knowledge/publications/adherence_ report/en/.

30. Garcia-Perez LE, Alvarez M, Dilla T, Gil-Guillen V, Orozco-Beltran D. Adherence to therapies in patients with type 2 diabetes. Diabetes Ther 2013;4:175-194.

31. Ko SH, Kim DJ, Park JH, et al. Trends of antidiabetic drug use in adult type 2 diabetes in Korea in 2002-2013: nationwide population-based cohort study. Medicine (Baltimore) 2016;95:e4018.

32. Kim HJ, Kim YG, Park JS, Ahn YH, Ha KH, Kim DJ. Association between blood glucose level derived using the oral glucose tolerance test and glycated hemoglobin level. Korean J Intern Med 2016;31:535-542.

33. Forbes JM, Cooper ME. Mechanisms of diabetic complications. Physiol Rev 2013;93:137-188.

34. Nathan DM; DCCT/EDIC Research Group. The diabetes control and complications trial/epidemiology of diabetes interventions and complications study at 30 years: overview. Diabetes Care 2014;37:9-16.

35. Zoungas S, Woodward M, Li Q, et al. Impact of age, age at diagnosis and duration of diabetes on the risk of macrovascular and microvascular complications and death in type 2 diabetes. Diabetologia 2014;57:2465-2474.

36. Lee WJ, Sobrin L, Lee MJ, Kang MH, Seong M, Cho H. The relationship between diabetic retinopathy and diabetic nephropathy in a population-based study in Korea (KNHANES V-2, 3). Invest Ophthalmol Vis Sci 2014;55:65476553.

37. Won JC, Kwon HS, Kim CH, et al. Prevalence and clinical characteristics of diabetic peripheral neuropathy in hos- pital patients with type 2 diabetes in Korea. Diabet Med 2012;29:e290-e296.

38. Jin DC. Major changes and improvements of dialysis therapy in Korea: review of end-stage renal disease registry. Korean J Intern Med 2015;30:17-22.

39. Rhee SY, Chon S, Kwon MK, et al. Prevalence of chronic complications in Korean patients with type 2 diabetes mellitus based on the Korean National Diabetes Program. Diabetes Metab J 2011;35:504-512.

40. Koo BK, Lee CH, Yang BR, Hwang SS, Choi NK. The incidence and prevalence of diabetes mellitus and related atherosclerotic complications in Korea: a National Health Insurance Database Study. PLoS One 2014;9:e110650.

41. Byun SH, Ma SH, Jun JK, Jung KW, Park B. Screening for diabetic retinopathy and nephropathy in patients with diabetes: a nationwide survey in Korea. PLoS One 2013;8:e62991.

42. Shi Y, Hu FB. The global implications of diabetes and cancer. Lancet 2014;383:1947-1948.

43. Chung JH, Moon K, Kim do H, Min JW, Kim TH, Hwang HJ. Suicidal ideation and suicide attempts among diabetes mellitus: the Korea National Health and Nutrition Examination Survey (KNHANES IV, V) from 2007 to 2012. J Psychosom Res 2014;77:457-461.

44. Han SJ, Kim HJ, Choi YJ, Lee KW, Kim DJ. Increased risk of suicidal ideation in Korean adults with both diabetes and depression. Diabetes Res Clin Pract 2013;101:e14-e17.

45. Lee YJ, Kang HM, Kim NK, et al. Factors associated for mild cognitive impairment in older Korean adults with type 2 diabetes mellitus. Diabetes Metab J 2014;38:150-157. 